\title{
MODELLING AND CHARACTERIZATION OF LASER WELDED INCOLOY 800 HT JOINTS
}

\author{
Srirangan Arun Kumar', Sathiya Paulraj ${ }^{1}$ \\ Department of Production Engineering, National Institute of Technology Tiruchirappalli-620015, Tamilnadu, \\ India, e-mail: psathiya@nitt.edu; arun1988@gmail.com
}

Received: 2016.04.15

Accepted: 2016.05.13

Published: 2016.06.01

\begin{abstract}
This study aims at finding the effect of laser welding speed on incoloy 800 HT. This alloy is one of the potential materials for Generation IV nuclear plants. Laser welding has several advantages over arc welding such as low fusion zone, low heat input and concentrated heat intensity. Three different welding speeds were chosen and $\mathrm{CO}_{2}$ laser welding was performed. 2D modeling and simulation were done using ANSYS 15 to find out the temperature distribution at different welding speeds and it was found that an increase in the welding speed decreased the temperature. Mechanical properties such as tensile strength, toughness and hardness were evaluated. The effect of welding speed on metallurgical characteristics was studied using optical microscopy (OM), Scanning Electron Microscopy (SEM) with EDS, X-Ray Diffraction (XRD) technique and fractographic analysis. From the results it was found that high welding speed (1400 $\mathrm{mm} / \mathrm{min}$ ) decreased the joint strength. The M23C6 and Ni3Ti carbides were formed in a discrete chain and in a globular form along the grain boundaries of the weld region which increased the strength of the grain boundaries. Fractographic evaluations of the tested specimens for welding speed (1000 and 1200) $\mathrm{mm} / \mathrm{min}$ showed deep and wide dimples indicating ductile failures.
\end{abstract}

Keywords: Incoloy 800 HT, laser welding, modeling and simulation, mechanical and metallurgical characteristics.

\section{INTRODUCTION}

Incoloy $800 \mathrm{HT}$, which comes under the family of austenitic nickel-chromium-based super alloys, exhibits good strength, excellent resistance to carburization and oxidation in high-temperature environment. So, it is broadly used in furnace equipment and components, petrochemical furnace cracker tubes, pigtails and headers, and used for sheathing of electrical heating elements due to its high creep rupture strengths, and resistance to high temperature corrosion [1]. Alloy $800 \mathrm{H}$ is one of the potential candidate alloys for Generation IV nuclear plants [2]. In these applications, the alloy may be exposed to continuous loading, cyclic loading, or then in combinations at elevated temperatures. As a result of the existence temperature gradient during welding process, the material undergoes various physical and chemical changes. Hence, the physical and chemical changes should be within the permissible limit to produce a good quality joint. The intense concentration of high heat input during arc welding process would lead to wider heat affected zone and sensitization issues in nickel alloys. Laser welding is one of the best alternative methods which can overcome the above mentioned problem. Laser welding can also be used for welding dissimilar materials [3-5]. Laser welding is a process, in which a highly coherent and monochromatic beam of laser is made to fall upon a narrow area where weld is required. Due to high power density of laser beam, the material melts and even vaporizes. After solidification the required weld is obtained. The laser beam is focused on very small area in which fast heating of target area and high cooling of molten material 
Table1. Chemical composition of the base material

\begin{tabular}{|c|c|c|c|c|c|c|c|c|c|}
\hline $\mathrm{C}$ & $\mathrm{Mn}$ & $\mathrm{S}$ & $\mathrm{Si}$ & $\mathrm{Cu}$ & $\mathrm{Cr}$ & $\mathrm{Fe}$ & $\mathrm{Al}$ & $\mathrm{Ti}$ & $\mathrm{Ni}$ \\
\hline 0.065 & 0.688 & $<0.010$ & 0.094 & 0.091 & 20.79 & 46.30 & 0.477 & 0.380 & 30.65 \\
\hline
\end{tabular}

occur. Laser welding consists of complex thermal cycles due to which analytical modelling is very difficult. So generally numerical modelling is adopted for obtaining these thermal cycles. Laser welding has various features such as low heat input, deep penetration, less heat affected zone, high speed and non-contact welding [6-9]. Over the other welding processes, laser welding can easily weld material up to $12 \mathrm{~mm}$ of thickness by using $\mathrm{CO}_{2}$ laser [10]. Laser welding due to its numerous advantages finds application in aircraft industry, oil field drilling industry, military, bimetallic application, agriculture and trucking, automobile etc. Laser welding results in high strength, stiffness and accuracy of the welded joint[11]. Pei-quan Xu et al. [12] studied the characteristics of the microstructure of laser welded Ti-6Al-4V joint. They found that cooling rate which was a function of welding speed had great effect on phase transformation and they also concluded that existence of residual stresses in fusion zone was due to the plastic deformation which occured during welding process. M.J. Torkamany et al. [13] studied the mechanical and microstructure characterization of laser spot welded low carbon and austenitic stainless steel. Mirakhorl et al. [14] used pulsed laser welding to study the microstructure of duplex stainless steel. They found that depending upon the overlaps, two different zones were formed. In recent years, research works on laser butt-welded plate of Inconel 718 super alloy focused on the effect of heat treatment process on the microstructures and mechanical properties of the welded seam [15-17]. Asma Belhadj et al. [18] developed a three dimensional FE model to study the temperature history of laser welded magnesium alloy. A non-linear transient model was used for carrying out the simulation. N. Siva Shanmugam et al. [19] used finite element model for predicting weld bead geometry of laser welded AISI 304 stainless steel. The input parameters chosen by them were beam power, incident angle of beam, and beam exposure time. The effect of Marangoni convection on weld pool shape was studied by Ehlen et al. [20]. In this work the effect of welding power on dynamics of weld pool was also studied and it showed that various type of weld pool dynamics occured depending upon the power of laser. Temperature distributions, pressure, concentration of alloying element were also calculated in their work. The above literature clearly indicate that only a limited work was carried out in modelling of laser welding of incoloy 800 HT and on the characterization of welded joints. The present work uses finite element code Ansys 15.0 for finding temperature distribution of incoloy 800 HT during laser welding. A two dimensional model was considered for carrying out transient analysis for laser welding. $\mathrm{CO}_{2}$ laser with a wavelength of $10 \mu \mathrm{m}$ and $3 \mathrm{~kW}$ power was used for performing laser welding operation. The effect of welding speed on temperature distribution, mechanical property and microstructure characteristics were investigated.

\section{EXPERIMENTAL PROCEDURE}

The incoloy $800 \mathrm{HT} 4 \mathrm{~mm}$ thick sheet with a brushed surface of a 1.5-3.5 $\mu \mathrm{m}$ roughness, was used as the base metal. The composition of the alloy is presented in Table 1. The specimens were fabricated by laser welding with an argon shielding. A $4 \mathrm{~kW}$ maximum output continuous $\mathrm{CO}_{2}$ laser (TRUMPF TLC1005) was used to weld the straight-edge butt joint of the $150 \mathrm{~mm} \times 100 \times 4 \mathrm{~mm}$ sheets with no gaps in between. The base sheets were rigidly clamped to obtain low angle distortions of the joints. The laser beam was focused on the surface of the sheet with a spot radius of 1 $\mathrm{mm}$. A front and back shielding, provided by gas trailers, was supplied with argon gas at a flow rate of $15 \mathrm{l} / \mathrm{min}$ to protect the molten pool and heated zone from oxidation. The parameters for laser welding were selected following FEA modeling and mechanical, metallurgical characterization. The parameters chosen were $3 \mathrm{~kW}$ laser power,

Table 2. Process parameters and their levels

\begin{tabular}{|c|c|c|c|}
\hline Exp. no & $\begin{array}{c}\text { Welding speed } \\
(\mathrm{mm} / \mathrm{min})\end{array}$ & $\begin{array}{c}\text { Power } \\
(\mathrm{kW})\end{array}$ & Focal position $(\mathrm{mm})$ \\
\hline 1 & 1000 & 3 & -0.3 \\
\hline 2 & 1200 & 3 & -0.3 \\
\hline 3 & 1400 & 3 & -0.3 \\
\hline
\end{tabular}


and $1000 \mathrm{~mm} / \mathrm{min}, 1200 \mathrm{~mm} / \mathrm{min}$, and $1400 \mathrm{~mm} /$ min welding speeds and are presented in Table 2. The welded specimens were cut in the weld cross section and were polished with different grades of emery sheet followed by alumina polishing and diamond polishing to get $0.05 \mu \mathrm{m}$ finish. The etchant used for revealing the micrograph of the joint was $15 \mathrm{ml} \mathrm{HCl}+10 \mathrm{ml} \mathrm{HAC}+10 \mathrm{ml} \mathrm{HNO}_{3}$. Metallographic analyses like macro structure, microstructure, SEM with EDS and micro hardness characterisation were done to find the characteristics of the weldments. The SEM with EDS image was taken using Carl Zeiss $\sigma$ version machine in high vacuum mode. The XRD results were taken using D/Max ULTIMA III machine in continuous mode. The tensile test was carried out in a universal testing machine of 40 ton capacity according to ASME SEC IX standard. Microhardness survey was carried out using a HMV-2000 Vickers micro-hardness tester at $500 \mathrm{~g}$ load for $10 \mathrm{~s}$. The micro-hardness tests were performed on a transverse section of the weld centre in order to identify the possible effects of microstructural heterogeneities in the weld. The Charpy test specimens were prepared according to the ASTM E-23 standard. The impact toughness of the joints was determined by pendulum impact testing machine at room temperature.

\section{FINITE ELEMENT MODEL}

A 2D finite element model was used for analyzing the temperature distribution of laser welding process using code Ansys 15. The reason for considering thermal analysis over mechanical analysis was that incoloy $800 \mathrm{HT}$ found application in high temperature environment of above $800^{\circ} \mathrm{C}$ and hence the main focus was on the stability at high temperature. Transient analysis was performed for carrying out the analysis. The properties chosen were thermal conductivity, specific heat $460 \mathrm{~J} / \mathrm{kg}^{\circ} \mathrm{C}$ and density $\left(7.95 \mathrm{~g} / \mathrm{cm}^{3}\right)$. Thermal conductivity was considered to be a function of temperature. Since the welded joint were symmetrical subjected to welding line, one plate as a half welded joint was considered for the analysis which resulted in reduction of computational time. Plane 77 element was chosen for analysis. The diameter of laser beam used for welding was $2 \mathrm{~mm}$. The following assumptions were made while modeling. The initial temperature of work piece was $30^{\circ} \mathrm{C}$. The Specific heat and density was considered constant with respect to time whereas thermal conductivity was considered as a function of time. The energy absorbed by the plate was $69.3 \%$ of incident energy as proposed by Xie and Kar [21]. The Marangoni effect, convective metal flow, buoyancy force were neglected and only conduction and convection phenomenon were considered.

Governing equation and boundary equation: since the analysis was transient, the temperature field would be the function of time $(t)$ and space coordinate $(x, y$, and $z)$.

Temperature distribution in laser welding can be expressed by equation (1):

$$
\rho C \frac{\partial T}{\partial t}=\nabla(K \nabla T)-\rho C U . \nabla T
$$

In modeling of welding process, weld pool stirring effect was ignored. Since only maximum temperature was required to be calculated in this work, temperature gradient in depth direction was neglected and the heat flow was assumed to be in 2 dimensions only. The heat flow can be modeled using equation (2):

$$
\rho C \frac{\partial T}{\partial t}=k(T)\left\{\frac{\partial^{2} T}{\partial x^{2}}+\frac{\partial^{2} T}{\partial y^{2}}\right\}+\frac{\partial k}{\partial T}\left\{\left(\frac{\partial T}{\partial x}\right)^{2}+\left(\frac{\partial T}{\partial y}\right)^{2}\right\}+\bar{Q}_{G}
$$

In the simplest scenario, the following assumptions were made. The only heat source acting on the surface was welding source and so no other heat source is considered. No heat was produced in any other region of work piece.

$$
\overline{\mathrm{Q}}_{\mathrm{G}}=\mathrm{q}
$$

The heat transfer during welding can be expressed as follows:

$$
\frac{\partial T}{\partial t}=\alpha\left\{\frac{\partial^{2} T}{\partial x^{2}}+\frac{\partial^{2} T}{\partial y^{2}}\right\}+q
$$


Initial condition is as follow:

$$
T(x, y, z, 0)=T_{0}(x, y, z)
$$

Boundary condition is following:

$$
\{q\}^{T} \cdot\{\eta\}=h_{f}\left(T_{B}-T_{S}\right)
$$

where $\{q\}^{T}$ is the heat flux field, $\{\eta\}$ is the unit outward normal vector, $h_{f}$ is the film coefficient, $T_{B}$ is the bulk temperature of adjacent fluid, $\mathrm{T}_{\mathrm{S}}$ is the temperature at surface of weldment,

It is assumed that laser beam form a disk like shape on the surface of weldment during simulation. The resulting heat distribution is described by following Gaussian function:

$$
\begin{gathered}
q(x, \zeta)=\frac{3 Q}{\pi c^{2}} \exp \left(-\frac{3 x^{2}}{c^{2}}\right) \exp \left(-\frac{3 \zeta^{2}}{c^{2}}\right) \\
\zeta=x-u \cdot t
\end{gathered}
$$

where: $\mathrm{u}$ - moving heat source in the $\mathrm{x}$-direction of the work plane at a constant velocity, ${ }^{*} \mathrm{Q}$ - energy input rate (W), $\mathrm{c}$ - characteristic radius of the heat flux distribution (m).

Figure 1 shows the simulation results of temperature distribution during laser welding (welding speed 1000, 1200, $1400 \mathrm{~mm} / \mathrm{min}$ ) on half welded joint with incoloy $800 \mathrm{HT}$ at different intrevals of time.
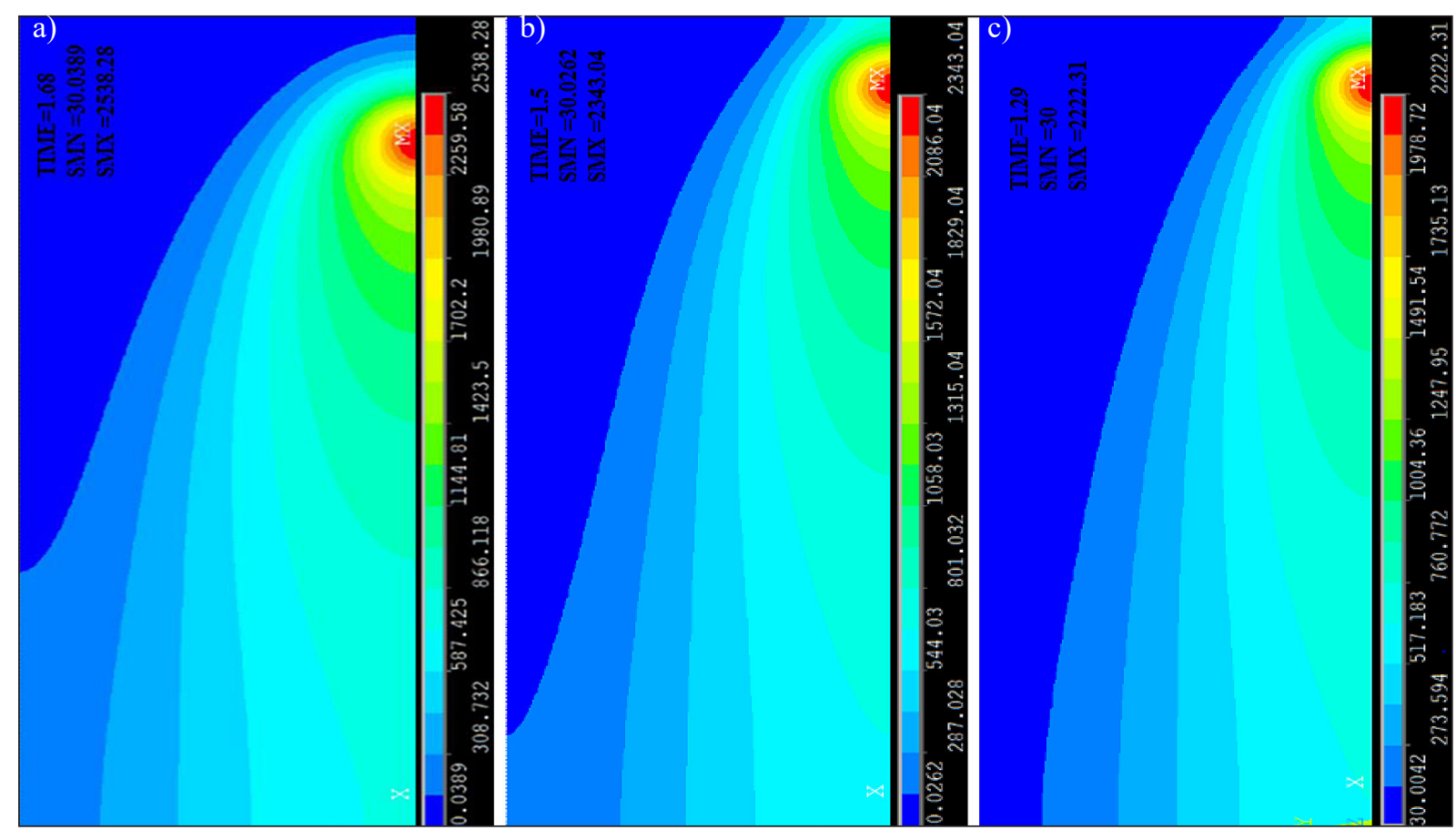

Fig. 1. Isotherm evolution during laser welding at different welding speeds: a) $1000 \mathrm{~mm} / \mathrm{min}$, b) $1200 \mathrm{~mm} / \mathrm{min}$, c) $1400 \mathrm{~mm} / \mathrm{min}$

\section{RESULTS AND DISCUSSION}

From Figure 2 it can be observed that with increase in welding speed, the heat input to the work piece decreased which resulted in reduction of peak temperature. However excess welding speed could cause lack of penetration. Keeping the factor in mind, the range of welding speed selected was $1000 \mathrm{~mm} / \mathrm{min}$ to $1400 \mathrm{~mm} / \mathrm{min}$ so as to get full depth of penetration and minimum heat affected zone.

Figure 3 shows the variation of thermal conductivity with temperature. As seen from the graph with increase in temperature thermal conductivity increased which further resulted in more heat conduction from weld zone and reduced the temperature of weld pool. Figure 4 $(a, b, c)$ shows how the peak temperature will 


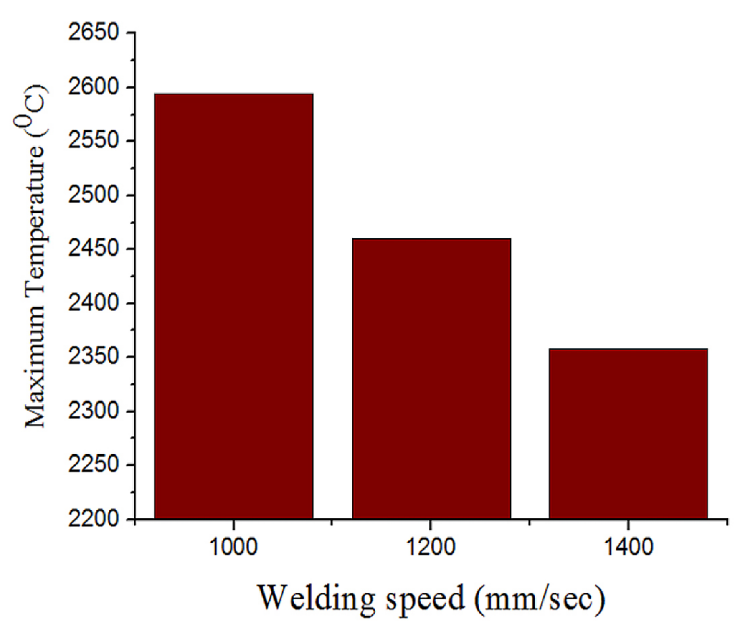

Fig. 2. Maximum temperature attained vs welding speed

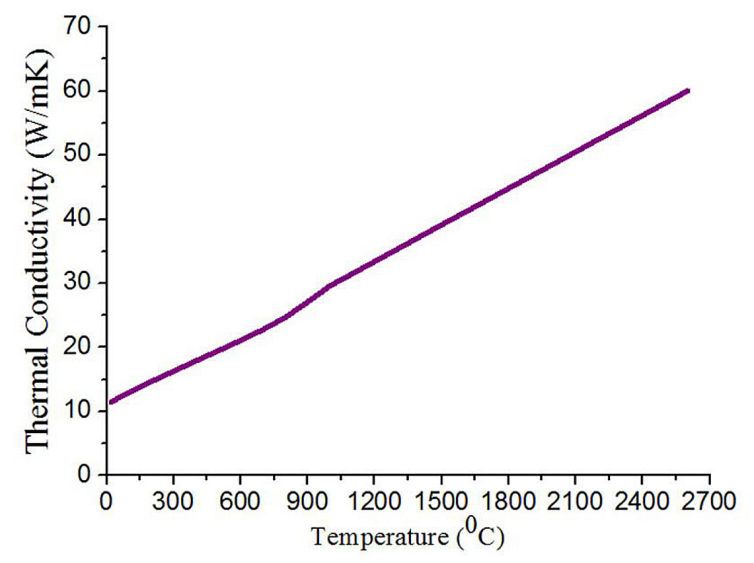

Fig. 3. Variation of thermal conductivity with respect to temperature

vary with time for welding speed of $1000 \mathrm{~mm} /$ $\mathrm{min}, 1200 \mathrm{~mm} / \mathrm{min}$ and $1400 \mathrm{~mm} / \mathrm{min}$. From the trend of graph for all three welding speed it can be seen that initially the rate of increase of temperature was very high and after some time it started to stabilize and this happened due to increase in thermal conductivity of material with temperature.

Figure $5(\mathrm{a}, \mathrm{b}, \mathrm{c})$ shows the comparison between the temperature distribution for $1000 \mathrm{~mm} /$ $\mathrm{sec}, 1200 \mathrm{~mm} / \mathrm{sec}$ and $1400 \mathrm{~mm} / \mathrm{sec}$. The point (area) considered was within the fusion zone and in the direction of welding. The measurement was done at a distance of $(2,4,6,8,10$, and 12) $\mathrm{mm}$ from the starting point of plate in the longitudinal direction. The trend of the curve was same for all welding speed and the only change was in the value of temperature. It can be seen that moving forward in the direction of welding, the slope of heating curve started decreasing for all welding speed and this was due to the fact a)

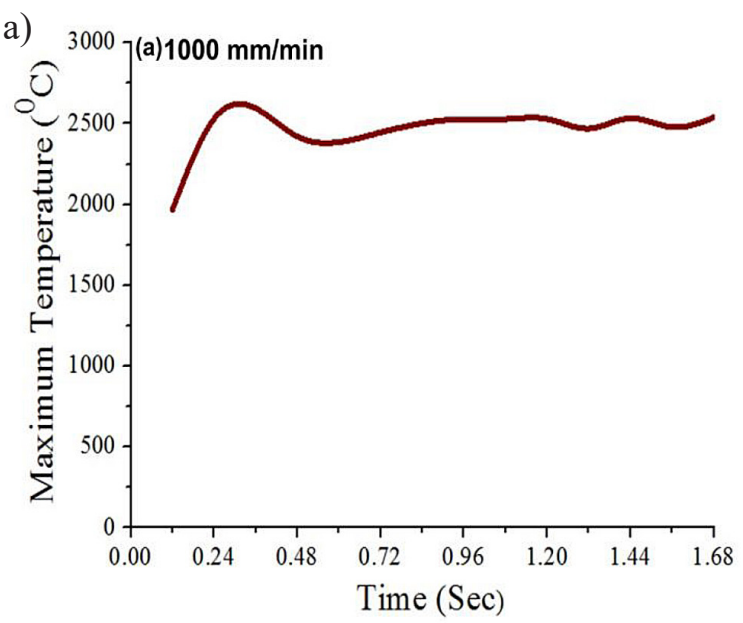

b)
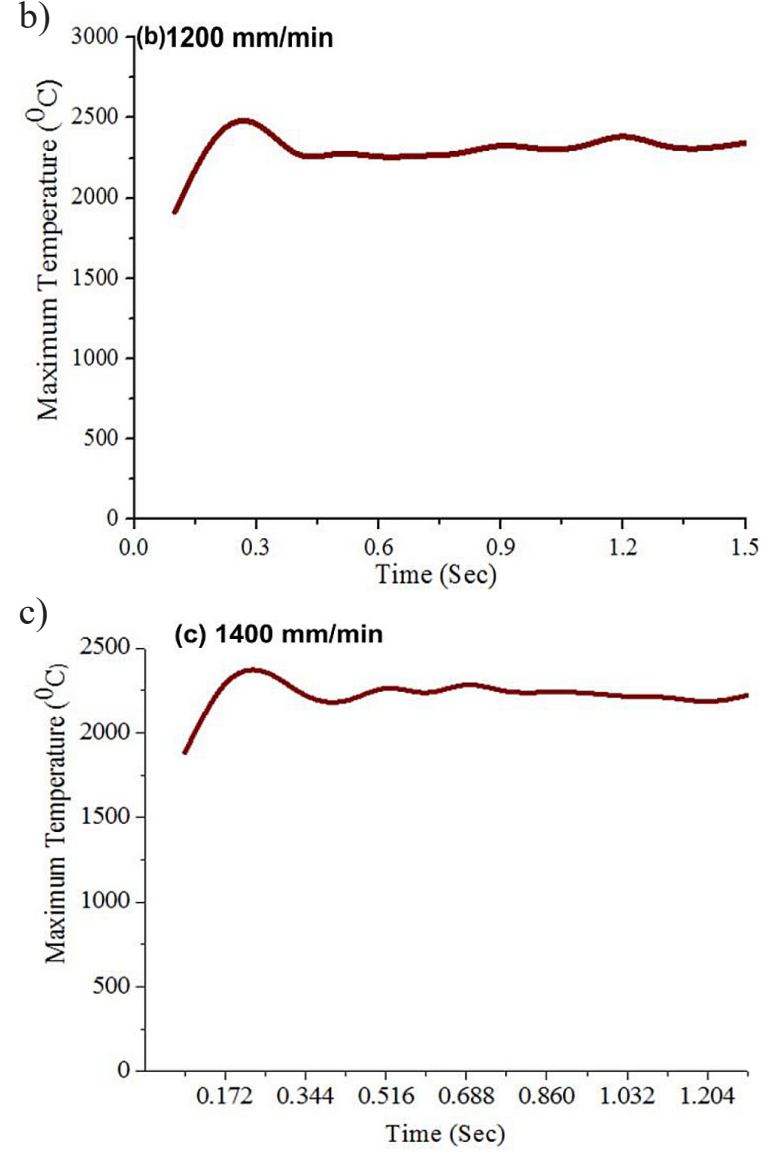

Fig. 4. Maximum temperature with respect to time at different welding speeds: a) $1000 \mathrm{~mm} / \mathrm{min}$,

b) $1200 \mathrm{~mm} / \mathrm{min}$, c) $1400 \mathrm{~mm} / \mathrm{min}$

that initially i.e. at starting point of welding, the temperature was environmental only $\left(300{ }^{\circ} \mathrm{C}\right)$ whereas as laser moved forward the temperature would be greater than environmental due to transfer of heat through conduction, which caused reduction of heating rate. Considering the cooling curve, with increase in time the rate of cooling decreased and this was because of reduction of temperature difference between welded plate and atmosphere. 
a)

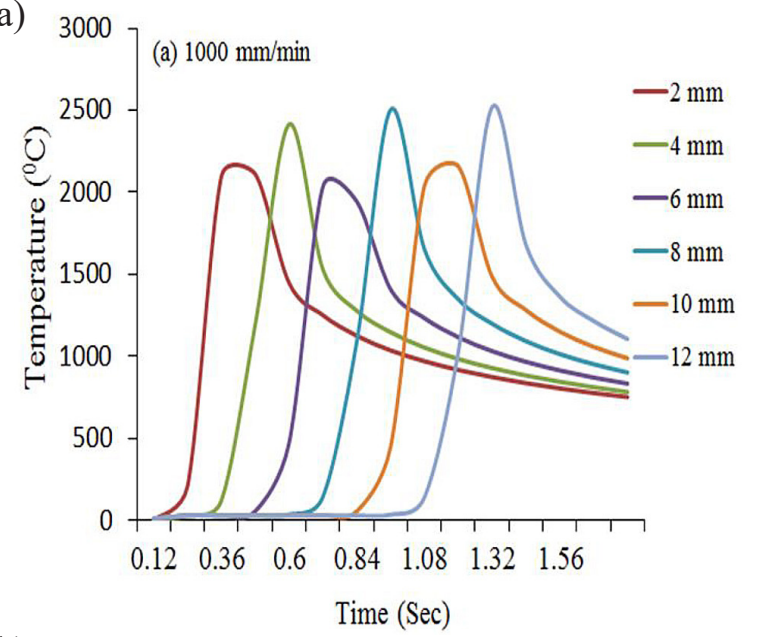

b)

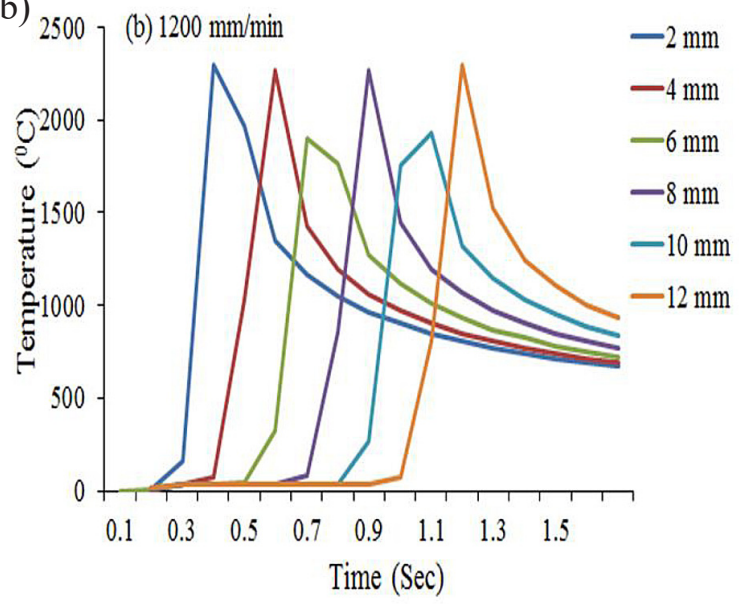

c) 2500

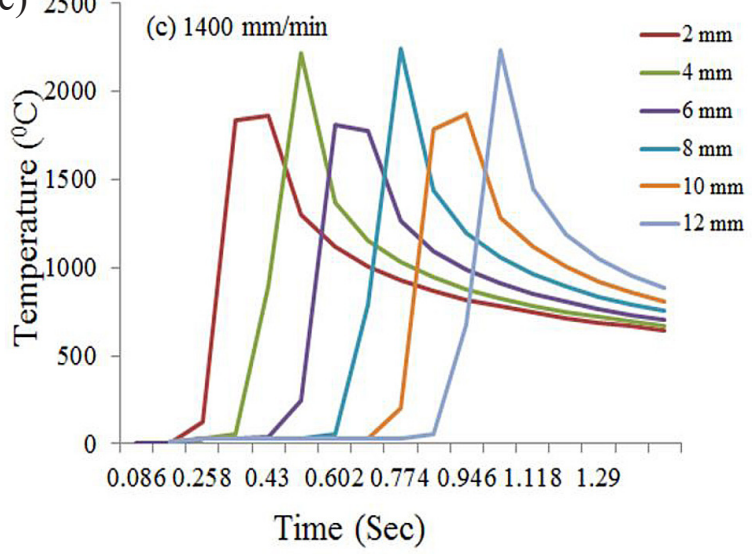

Fig. 5. Comparison of temperature distribution at different welding speeds

The above graph (figure 6) shows the temperature distribution when the region is $2 \mathrm{~mm}$ and $2.5 \mathrm{~mm}$ away from weld center line. The above reading was taken for welding speed of $1200 \mathrm{~mm} /$ min which gave better result as compared to other welding speed in this case. Figure 8 basically shows the difference between slope of heating and cooling during laser welding process. From figure 8 we can conclude that an increase in distance from the weld centre line decreased the peak tem-

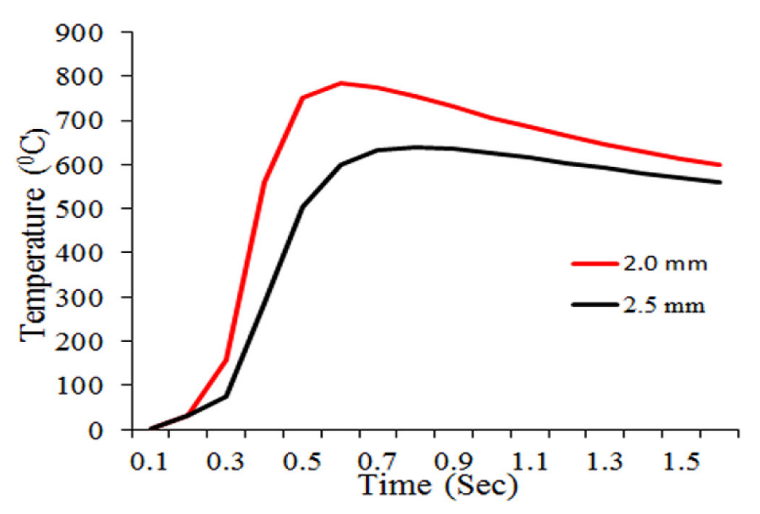

Fig. 6. Temperature distribution at $2 \mathrm{~mm}$ and $2.5 \mathrm{~mm}$ away from the fusion zone with respect to time

perature, decreased the rate of heating and cooling, increased time to attain peak temperature and decreased rate of cooling with increase in time.

\section{Mechanical properties of the weld joint}

The mechanical properties of the weld joints are shown in Table 3.

It can be seen from the table that higher welding speed has led to decreased strength of the joints. For the Experiment 3 the the hardness values increased and the toughness, tensile strength of the joint decreased due to the higher cooling rate which has caused brittleness of the material. The fracture during tensile testing occurred at the weld region for experiment 3 and approximately $10 \mathrm{~mm}$ away from the weld region for experiment 1 and 2 which can be seen from figure. Also the tensile strength of the weld joint experiment

Table 3. Mechanical properties of the weld joints

\begin{tabular}{|c|c|c|c|c|}
\hline $\begin{array}{c}\text { Experiment } \\
\text { number }\end{array}$ & $\begin{array}{c}\text { Yield } \\
\text { strength } \\
(\mathrm{MPa})\end{array}$ & $\begin{array}{c}\text { Tensile } \\
\text { strength } \\
(\mathrm{MPa})\end{array}$ & $\begin{array}{c}\text { Toughness } \\
(\mathrm{J})\end{array}$ & $\begin{array}{c}\text { Hardness } \\
(\mathrm{HV})\end{array}$ \\
\hline 1 & 399.15 & 605.27 & 62 & 170 \\
\hline 2 & 395.15 & 622.84 & 64 & 184 \\
\hline 3 & 311.04 & 533.25 & 48 & 202 \\
\hline
\end{tabular}

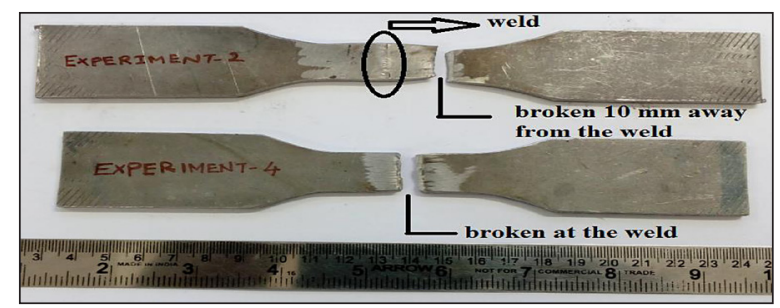

Fig. 7. Figure showing the fracture location of the tensile tested sample 

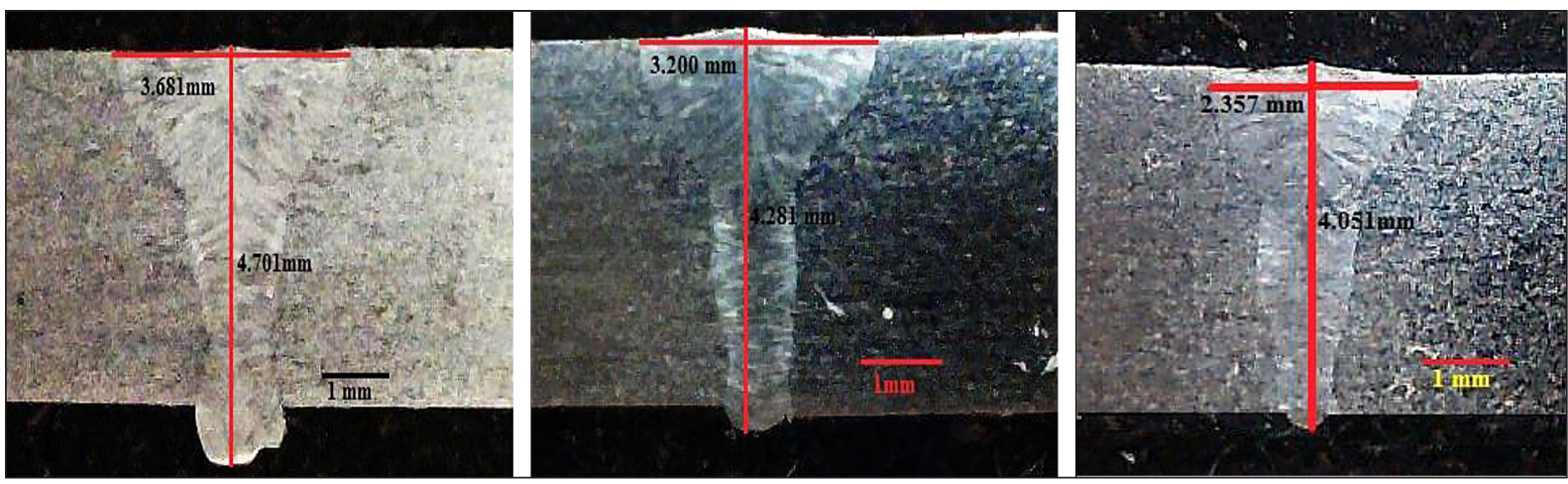

Fig. 8. Macrostructure of the welded specimen at welding speed: a) $1000 \mathrm{~mm} / \mathrm{min}$,

b) $1200 \mathrm{~mm} / \mathrm{min}$, c) $1400 \mathrm{~mm} / \mathrm{min}$

3 was less than that of the base material tensile strength (540 MPa).

\section{Macrostructure of the welded specimen}

Figure 8 shows the macrostructure of the weld region with three different welding speeds. The weld bead width and depth were measured using IMAGE-J software. It was clear from the Figure that higher welding speed decreased the amount of molten metal penetrated. This was due to the variation in the peak temperature at the fusion zone for different welding speeds which can be seen from the isotherms obtained in FEA simulation.

\section{Microstructure analysis:}

Figure 9 shows the microstructure of incoloy $800 \mathrm{HT}$ as received in mill and annealed condition. The microstructure consisted of a solid solution matrix in which some grains were delineated by precipitate particle at the boundaries and by twining lines.

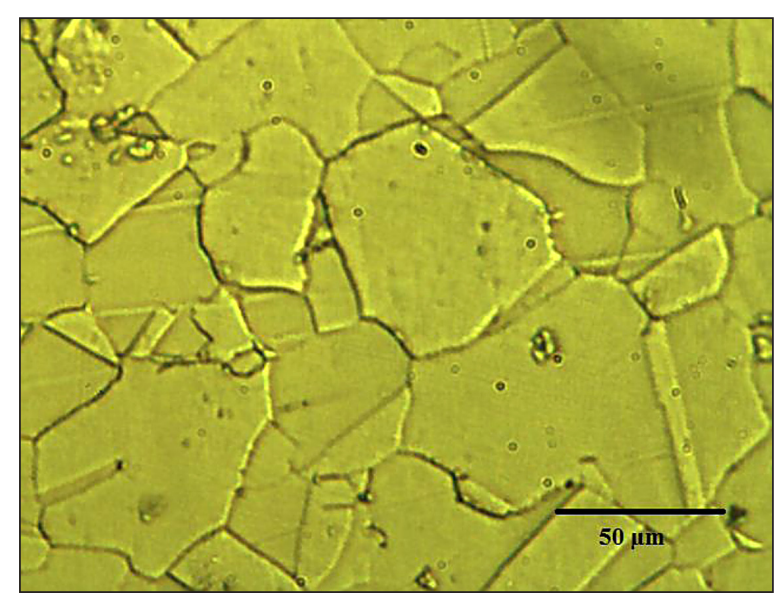

Fig. 9. Microstructure of the base metal incoloy $800 \mathrm{HT}$
In laser welding cooling rate is very high, around $1000-10000{ }^{\circ} \mathrm{C} / \mathrm{sec}$. High temperature gradient resulted in narrow heat-affected zone and no sensitization could happen. High cooling rate affected the microstructure of the weld and it exhibited very fine grain structure and the order of magnitude was finer than that of TIG weld [22].

Depending on composition and welding parameters, Austenitic stainless steel welds can solidify in different modes primary austenitic or primary ferritic ways. In addition five different solidification modes differed depending on the fact whether the secondary phase transformed from the remaining melt or in the solid phase [23].

The solidification mode was strongly dependent on the composition. The limits for the solidification modes could be calculated by chromium and nickel equivalents. Roughly, if the ratio of chromium and nickel equivalents was below 1.5, the solidification was fully austenitic or austenitic-Ferritic and when it was between $1.5-2.0$ it was Ferritic austenitic. In the values over 2.0 solidification was austenitic-Ferritic. These numbers depended, a bit on equivalents used [24]. For incoloy 800 HT the ratio of nickel and chromium equivalent is below 1.2 which revealed that the solidification mode was fully austenitic.

When cooling rate (and solidification rate) was more rapid as in the case of laser welding, the boundaries between solidification modes came closer to each other. This is natural, because in rapid cooling diffusion controlled solidstate transformation does not have that much time to occur.

Figure 10a and 10b show the microstructure of the welded zone for experiment 1 and 3. Incoloy 800 HT has a chromium nickel equivalent ratio less than 1.2 and due to the higher welding speed, a fully austenitic finer cellular dentritic structure 


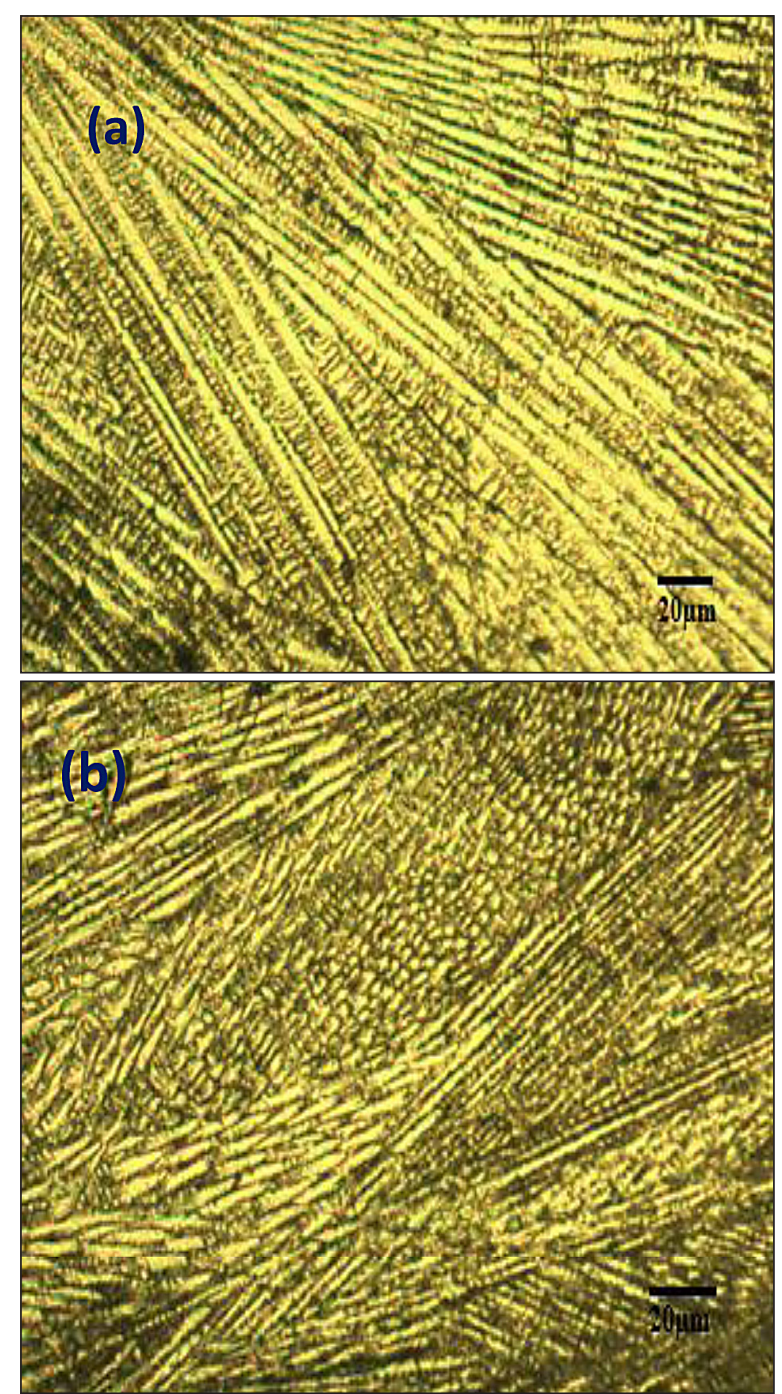

Fig. 10. SEM image of the weld region corresponding to the welding speed: a) $1000 \mathrm{~mm} / \mathrm{sec}$, b) $1400 \mathrm{~mm} / \mathrm{sec}$

was observed on the weld region.Much finer microstructure of the laser welds would refer to a lower microsegregation during solidification of the welds. In Figure 10(a) coarser was the dendritic structure compared to 10(b) due to the decreasing cooling rate. The microstructure showed pronounced grain growth subsequent to recrystallization as a result of the high temperatures reached during welding which can also be seen from Figure 2. It may also be noticed that most of the precipitates in the original base material got dissolved and re-precipitation had occurred on cooling predominantly along the grain boundaries.

The noticeable feature was the highly directional nature of the microstructure around the axis of the laser beam and a very narrow heat affected zone (Figure 11). This was due to solidification of the weld metal at high cooling rate compared
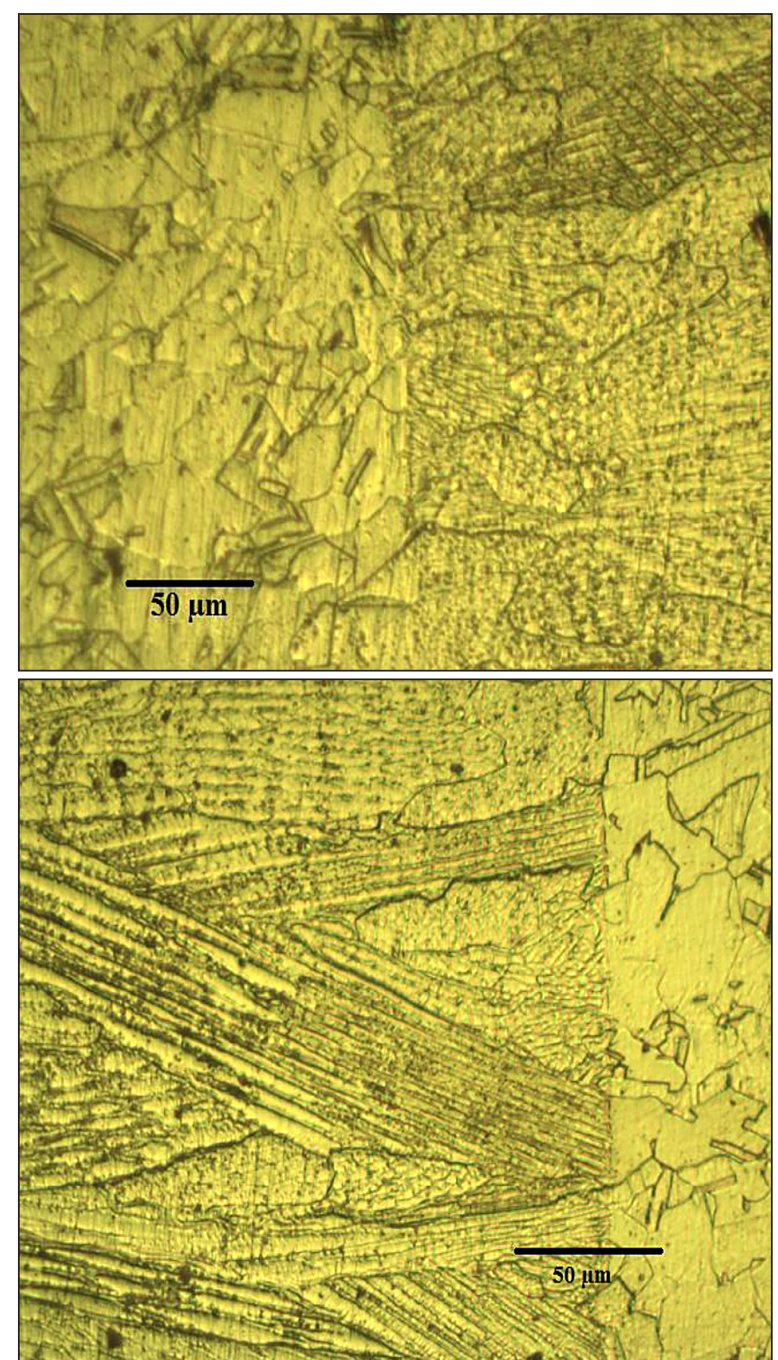

Fig. 11. Microstructure of the weld interface at $1200 \mathrm{~mm} / \mathrm{min}$

to that of conventional GTA welding. It can also be noticed that the higher the welding speed, the finer was the dendritic structure. This is attributed to an increase in both solidification and cooling rates due to low heat input resulted from high welding speed.

\section{EDS and XRD analysis}

The most important carbide in super alloy is M23C6, which forms grain boundaries during ageing and when properly formed increases the strength of the grain boundaries to balance the matrix strength. Figure 12 shows the SEM with EDS results in weld region for experiment 2 . The main composition consists of $\mathrm{Ni}, \mathrm{Cr}, \mathrm{Fe}, \mathrm{Ti}$ and $\mathrm{C}$. The grain boundary particles have a high $\mathrm{Cr}$, $\mathrm{Ni}$ and $\mathrm{C}$ content with $\mathrm{Fe}$ (see EDS spectrum in Figure 14). A previous study indicated that chromium carbides were precipitated in the al- 

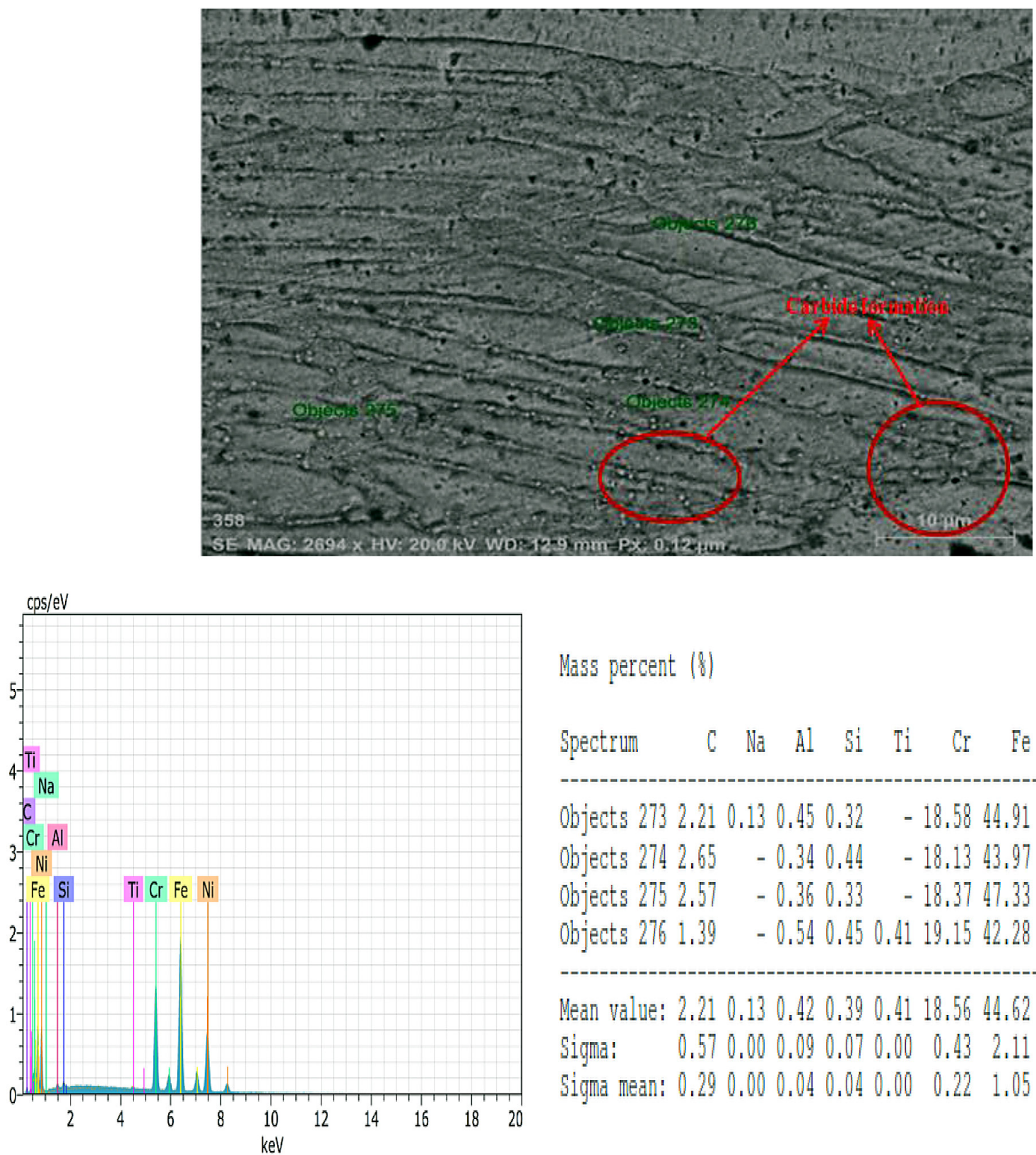

Mass percent (8)

Spectrum C $\quad \mathrm{Na}$ Al Si $\mathrm{Ti}$ Cr

Objects $2732.210 .130 .450 .32 \quad-18.5844 .9129 .17$

objects $2742.65-0.340 .44-18.1343 .9731 .29$

objects $2752.57-0.360 .33-18.3747 .3332 .16$

objects $2761.39-0.540 .450 .4119 .1542 .2828 .42$

Fig. 12. SEM with EDS result taken at the weld region (welding speed $1200 \mathrm{~mm} / \mathrm{min}$ )

loy at temperatures between 540 and $10950{ }^{\circ} \mathrm{C}$ [25]. Other studies also suggested that the carbides were identified as type M23C6 precipitates $(\mathrm{M}=\mathrm{Cr}, \mathrm{Fe})$.Therefore, the particles at the grain boundaries were likely to be chromium carbides and titanium carbides. From the results reported previously [26-28], it is also speculated that the very fine intragranular precipitates were likely to be MC type carbides.

The EDS results were taken at four different points to accurately predict the particles present and XRD analysis was also made at the weld region (Figure 12 and 13). From the EDS results it was clear that the particles present at the grain boundaries were M23C6 and Ni3Ti. Corrosion resistance was provided by the formation of a chromium-rich passive layer. When exposed to high temperatures localized chromium carbide precipitated. Typically, the $\mathrm{Cr}$ carbide was $\mathrm{Cr}$ enriched M23C6, in which $\mathrm{M}$ represented $\mathrm{Cr}$ and some small amount of Fe. M23C6 particles when present as a chain of discrete, globular particles at the grain boundary increased the strength of grain boundaries to balance the matrix strength. The XRD peak position were searched using a program utilizing ICDD PDF 2004 database and it was found that the peaks represent austenite phase comprising of $\mathrm{Fe}, \mathrm{Ni}$ and $\mathrm{Cr}$. The carbides were formed along the grain boundaries in the austenite matrix. 

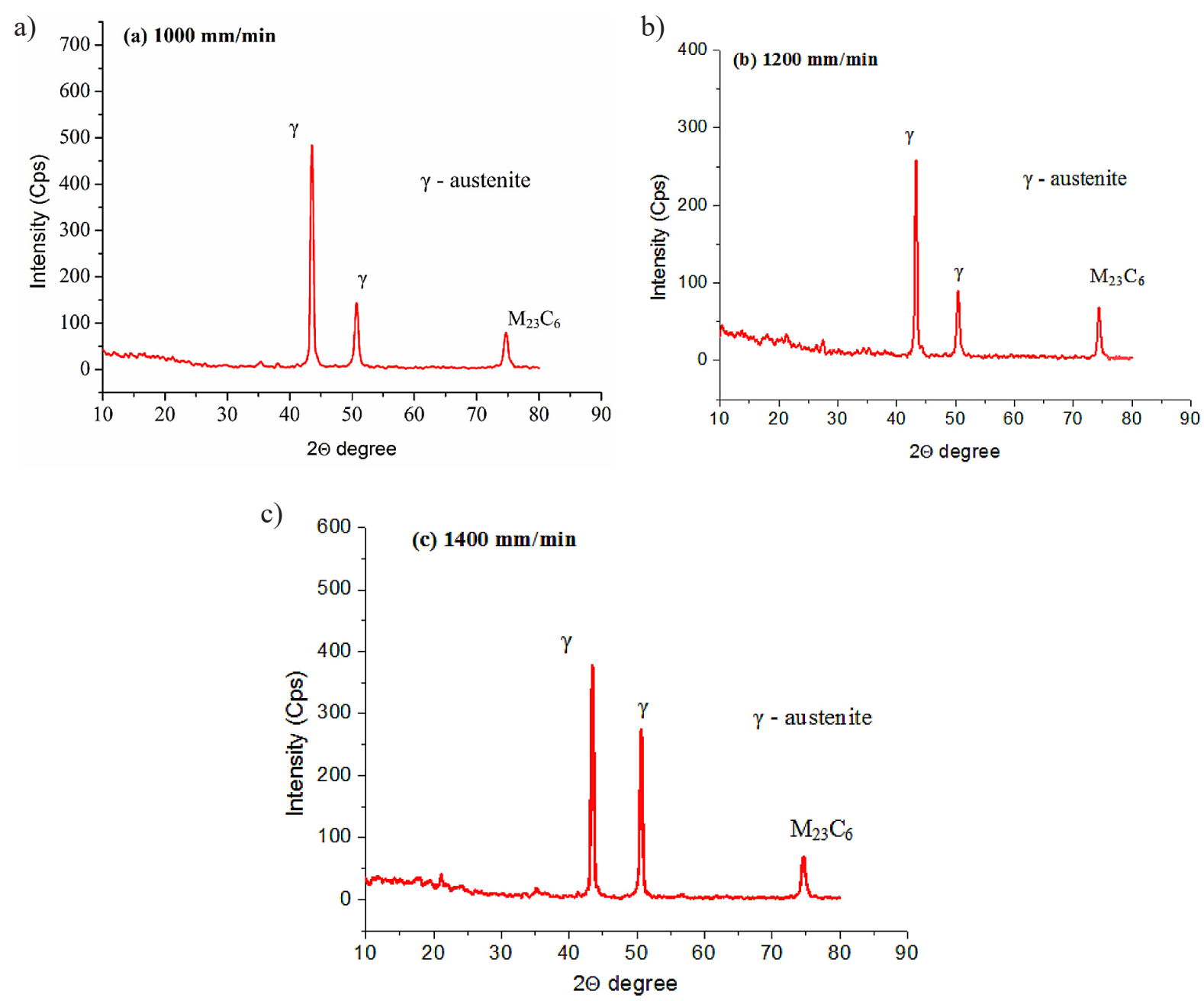

Fig. 13. XRD results from different welding speeds: a) $1000 \mathrm{~mm} / \mathrm{min}$, b) $1200 \mathrm{~mm} / \mathrm{min}$, c) $1400 \mathrm{~mm} / \mathrm{min}$

\section{Fractographic analysis}

Table 3 shows ultimate tensile strength, impact and hardness of the weld region. It is clear from the result that high welding speed (1400 $\mathrm{mm} / \mathrm{min}$ ) decreased the strength of the joints. So an optimum welding speed and power should be ensured for better strength. All the tensile tested specimens were fractured at the base material which indicated that the strength of the weld joint was more than the base material $(540 \mathrm{MPa})$. To analyze further the SEM image was taken on the fracture surface. There were two types of fracture, brittle and ductile, depending on the ability of the material to undergo plastic deformation before the fracture. The ductile mode of fracture undergoes extensive plastic deformation ahead of the crack and the crack was stable which could resist further extension unless the applied stress was increased. In brittle mode the crack was unstable and propagated rapidly without increase in applied stress. The ductile mode of fracture is pre- ferred in most of the applications. Figure 14(a,b) corresponds to the fractographic images taken for experiment 1 and 2 showed deep and wide dimples which revealed ductile fracture mode whereas Figure 14(c) which corresponds to experiment 3 showed mostly cleavages which revealed brittle mode of failure.

\section{CONCLUSION}

$\mathrm{CO}_{2}$ Laser welding was carried out using three different welding speeds on incoloy $800 \mathrm{HT}$. A 2D finite element modeling and simulation were done to find the temperature distribution during welding. The peak temperature tended to decrease with the increase in welding speed. The mechanical properties (tensile toughness and hardness) were evaluated according to standard procedure. The strength of the joints decreased at high welding speed $1400 \mathrm{~mm} / \mathrm{min}$ and higher strength was obtained on welding speed (1200 

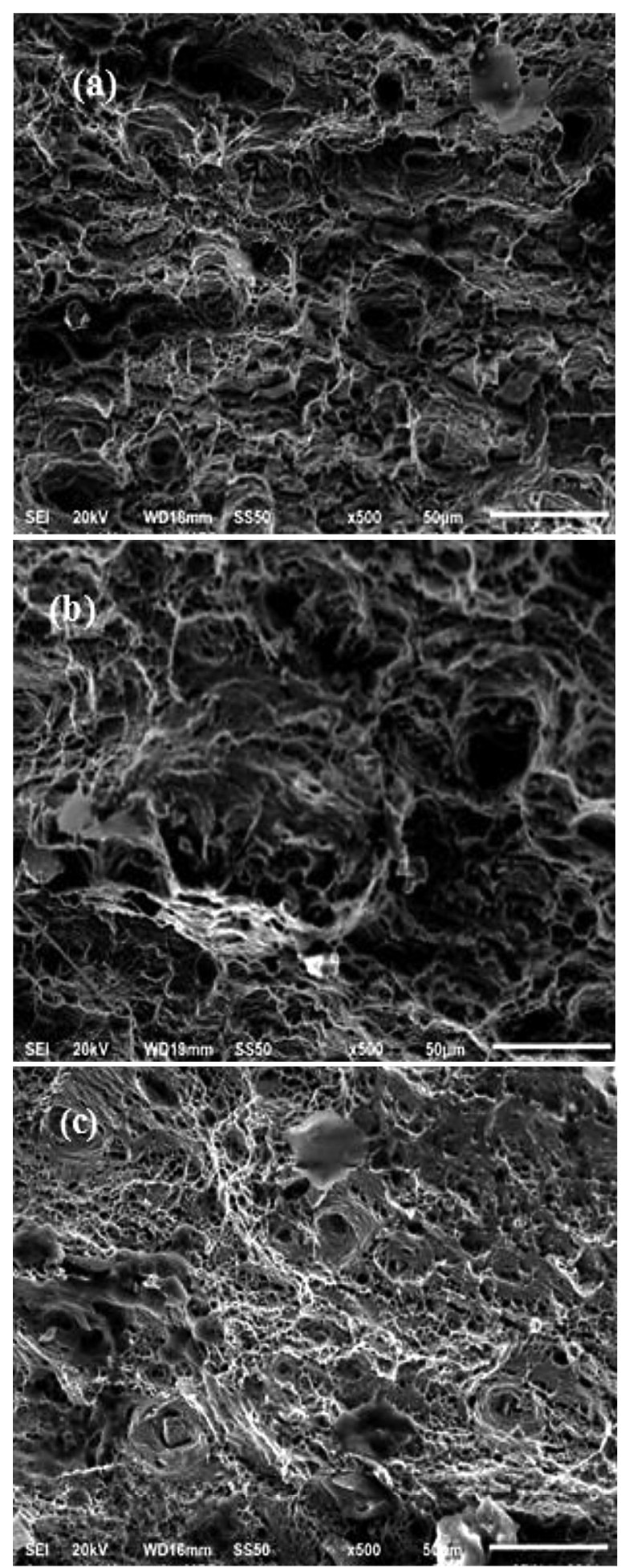

Fig. 14. Fractography of the tensile tested specimen from different welding speeds: a) $1000 \mathrm{~mm} / \mathrm{min}$,

b) $1200 \mathrm{~mm} / \mathrm{min}$, c) $1400 \mathrm{~mm} / \mathrm{min}$

$\mathrm{mm} / \mathrm{min}$ ). The microstructure features were highly directional due to higher welding speeds used in case of laser welding. The lower welding speed showed harder cellular dendrites compared to that which obtained from higher welding speed. The higher temperature resulted during welding had led to the formation of M23C6 and Ni3Ti precipitates in a discrete chain and globular form. This type of precipitates strengthened the grain boundaries. The precipitates formed were confirmed by taking EDS at the weld region. Fractographic evaluations of the tested specimens for welding $1400 \mathrm{~mm} / \mathrm{min}$ showed mostly cleavages indicating brittle failures.

\section{Acknowledgements}

The authors gratefully acknowledge Magod Laser Machining Pvt. Ltd., Bangalore, India for allowing us to carry out laser welding trials for this research work.

\section{REFERENCES}

1. Ganeshan P., Smith G.D., Tassen C.S.: Applications and Materials Performance. Proceedings of the Nickel Cobalt 97 International Symposium, Sudbury, Ontario, August 17-20, 1997, 97-111.

2. Next generation nuclear plant materials research and development program plan, INEEL/EXT-0402347, Idaho National Engineering and Environmental Lab., Bechtel BWXT Idaho, LLC, Idaho Falls, Idaho, Spet. 2004.

3. Olabi A.G., Alsinani F.O., Alabdulkarim A.A., Ruggiero A., Tricarico L., Benyounis K.Y.: Optimizing the $\mathrm{CO} 2$ laser welding process for dissimilar materials. Optics and Lasers in Engineering, 51, 2013, 832-839.

4. Mathieu A., Shabadi R., Deschamps A., Suery M., Matteï S., Grevey D., Cicala E Dissimilar material joining using laser (aluminum to steel using zincbased filler wire. Optics \& Laser Technology, 39, 2007, 652-661.

5. Chatterjee S., Abinandanan T.A., Chattopadhyay $\mathrm{K}$.: Phase formation in $\mathrm{Ti} / \mathrm{Ni}$ dissimilar welds. Materials Science and Engineering A, 490, 2008, 7-15.

6. Yue Wu., Yan Cai., Dawei Sun., Junjie Zhu., Yixiong Wu.: Characteristics of plasma plume and effect mechanism of lateral restraint during high power CO2 laser welding process. Optics \& Laser Technology, 64, 2014, 72-81.

7. Pan M.: Minimization of welding distortion and buckling. Woodhead Publishing Limited, 2011.

8. Amit K., Duck Y., Darek C.: Correlation analysis of the variation of weld seam and tensile strength in laser welding of galvanized steel. Optics and Lasers in Engineering, 51(10), 2013, 1143-1152.

9. Chen W., Paul A., Pal M.: CO2 laser welding of galvanized steel sheets using vent holes. Materials 
and Design, 30 (2), 2009, 245-251.

10. Qian M., Lippold JC.: Liquation phenomena in the simulated heat affected zone of alloy 718 after multiple post weld heat treatment cycles. Welding Journal, 6 (3), 2003, 145-150.

11. Honga J.K., Park J.H., Parka N.K., Eomc I.S., Kimc M.B., Kangc C.Y.: Microstructures and mechanical properties of Inconel 718 welds by $\mathrm{CO} 2$ laser welding. Journal of Materials Processing Technology, 201, 2008, 515-520.

12. Pei-quan Xu., Leijun Li., Chunbo (Sam) Zhang.: Microstructure characterization of laser welded Ti6Al-4V fusion zones. Materials Characterization, 87, 2014, 179-185.

13. Torkamany M.J., Sabbaghzadeh J., Hamedi M.J.: Effect of laser welding mode on the microstructure and mechanical performance of dissimilar laser spot welds between low carbon and austenitic stainless steels. Materials and Design, 34, 2012, 666-672.

14. Mirakhorli F., Malek Ghaini F., Torkamany M.J.: Development of Weld Metal Microstructures in Welding of Duplex Stainless Steel. Journal of Materials Engineering and Performance, 21 (2), 2012, 173-217.

15. Sgobbi S., Zhang L., Norris J., Richter K H., Loreau J H.: High powder $\mathrm{CO} 2$ and Nd YAG laser welding of wrought Inconel 718. Journal of Materials Processing Technology, 56, 1996, 333-345.

16. Janaki Ram G.D., Reddy A.V., Rao K.P., Reddy G.M., Sarin Sundar J.K.: Microstructure and Tensile Properties of Inconel 718 Pulsed Nd-YAG Laser Welds. Journal of Materials Processing Technology, 167, 2005, 73-82.

17. Gao Peng., Zhang Kai-feng., Zhang Bing-gang., Jiang Shao-song., Zhang Bao-wei.: Microstructures and high temperature mechanical properties of electron beam welded Inconel 718 super alloy thick plate. Transactions of Nonferrous Metals Society of China, 21, 2011, 315-322.

18. Asma Belhadj., Jamel Bessrour., Jean-Eric Masse., Mahmoud Bouhafs., Laurent Barrallier.: Finite ele- ment simulation of magnesium alloys laser beam welding. Journal of Materials Processing Technology, 210, 2010, 1131-1137.

19. Siva Shanmugam N., Buvanashekaran G., Sankaranarayanasamy K.: Some studies on weld bead geometries for laser spot welding process using finite element analysis, Materials \& Design, 34, 2012, 412-426.

20. Ehlen G., Ludwig A., Sahm P.R.: Simulation of time-dependent pool shape during laser spot welding: transient effects, Metallurgical and Materials Transactions A, 34, 2003, 2947-2961.

21. Xie J., Kar A.: Laser welding of thin sheet steel with surface oxidation. Welding Journal Research Supplement, 78, 1999, 343-348.

22. Veli Kujanpaa.: Thick-section laser and hybrid welding of austenitic stainless steels, Physics Procedia, 56, 2014, 630-636.

23. Suutala N., Takalo T., Moisio T.: Relationship between solidification and microstructure in austenitic and austenitic-ferritic stainless steel welds, Metallurgical and Materials Transactions A, 10 (4), 1979, 512-514.

24. Lippold, J.C.: Solidification behavior and cracking susceptibility of pulsed-laser welds in austenitic stainless steels, Welding Journal, 73 (6), 1994, 129-139.

25. Incoloy alloy $800 \mathrm{H}$ and $800 \mathrm{HT}$, Special Metals, www.specialmetals.com

26. Bhanu Sankara Rao K., et al.: On massive carbide precipitation during high temperature low cycle fatigue in alloy $800 \mathrm{H}$. Scripta Materialia, 31 (4), 1994, 381-386.

27. Viktor Guttmann and Jens Timm.: On the influence of the thermal pretreatment on creep and microstructure of alloy $800 \mathrm{H}$. Z Metallkd, 81 (6), 1990, 428-432.

28. Todd J.A., Ren J.: The effect of cold work on the precipitation kinetics of an advanced austenitic steel, Materials Science and Engineering: A, 117, 1989, 235-245. 